\title{
PENGARUH PEMBERIAN KOMPOS SAMPAH KOTA DAN UREA, TSP, KCL PADA REGOSOL TERHADAP SERAPAN HARA N, P, K, TANAMAN SELADA ( Lactuca sativa L )
}

\author{
Asmar dan Irwan Darfis \\ J urusan Tanah F akultas Pertanian U niversitas Andalas Padang
}

\begin{abstract}
A research about Effect of compost as well as Urea, TSP, and $\mathrm{KCl}$ fertilizer application in Regosol on nutrient N, P, K uptake by lettuce (Lactuca sativa, L), had been conducted from April to November 2008 in Glasshouse, agriculture Faculty Andalas University Padang. The objective of the research was to determine the effects of organic fertilizer (compost of market waste) appication and the best NPK fertilizer dossages on soil chemical properties of Regosol planted by lettuce. This research was a pot trial by using factorial design which was allocated as completely randomized in Glasshouse. There were two factors, 4 x 4 treatments tested in this experiment, with 3 replications. The first factor was dossage of compost $\left\{K_{0}=\right.$ Without compost, $\mathrm{K}_{1}=2,5 \mathrm{ton} / \mathrm{ha}(10 \mathrm{~g} / \mathrm{pot}), \mathrm{K}_{2}=5$ ton/ha $\left.(20 \mathrm{~g} / \mathrm{pot}), \mathrm{K}_{3}=10 \mathrm{ton} / \mathrm{ha}(40 \mathrm{~g} / \mathrm{pot})\right\}$ and the second factor was NPK dossage $\left(\mathrm{P}_{0}=\right.$ Without NPK, $\mathrm{P}_{1}=25 \%$ NPK recommendation, $\mathrm{P}_{2}=50$ $\%$ NPK recommendation, $\mathrm{P}_{3}=100 \%$ NPK recommendation). The data of this research were tested by using F-test at $5 \%$ level, and then continued by using HSD test. The results showed that application of 10 ton compost / ha could gave the highest $\mathrm{pH}$ value, total $\mathrm{N}$, available $\mathrm{P}$, CEC, Ca-exch, Mg-exch, K-exch, and Na-exch, but decreased Org-C of the soil. In general, the best interaction of both treatments was found under combination of 5 ton compost/ha and 25\% NPK recommendation for plant growth, plant dry matter, and NPK uptake by plants. Based on the research conducted, it was suggested that the best input for lettuce grown on Regosol was combination between 5 ton compost/ha and 25\% NPK recommendation for the plants.
\end{abstract}

Key Words: Compost, Regosol, Lettuce PENDAHULUAN

Pertambahan jumlah penduduk mengakibatkan meningkatnya kebutuhan pangan dan sayuran, sehingga perluasan areal pertanian dan pemanfaatan teknologi sangat diperlukan untuk memenuhi kebutuhan tersebut. Selain pertambahan penduduk, pembangunan yang semakin meningkat juga mengakibatkan berkurangnya lahan - lahan produktif untuk pertanian, sehingga lahan yang tinggal umumnya tanah - tanah marginal yang memiliki banyak masalah.

Regosol merupakan salah satu lahan marginal yang perlu mendapatkan perhatian. Tanah bertekstur kasar atau berpasir seperti Regosol memiliki produktifitas yang terbatas karena laju infiltrasi terlalu tinggi, sehingga dapat menyebabkan pencucian unsur hara pada tanah pasir yang mengakibat pemupukan tidak efisien.

Pada tanah pasir penambahan bahan organik akan mengikat butir - butir tanah menjadi agregat - agregat, sehingga mempertinggi kapasitas memegang air. Tanah pasir atau tanah yang mudah tererosi lebih baik dipupuk dengan pupuk organik dibandingkan dengan pupuk an organik karena pemberian pupuk an organik pada tanah tersebut akan mudah tercuci oleh air hujan. Dengan diberikan pupuk organik maka daya menahan air dan kation - kation meningkat sehingga pencucian oleh air hujan dan erosi dapat dikurangi ( Sutedjo, 2002 ).

Oleh karena itu, salah satu alternatif untuk mengatasi masalah tersebut adalah dengan menggunakan bahan organik untuk menambah ketersedian unsur hara pada tanah. Di mana penambahan bahan organik ke dalam tanah dapat memperbaiki sifat fisika, kimia dan biologi tanah kearah lebih 
baik dan secara tidak langsung dapat meningkatkan kesuburan tanah Husin (1986).

\section{METODE PENELITIAN}

Penelitian ini dilaksanakan di Rumah Kaca Fakultas Pertanian Universitas Andalas Limau Manis Padang. Analisis tanah dan tanaman dilaksanakan di Laboratorium Jurusan Tanah Fakultas Pertanian Universitas Andalas Padang. Penelitian dimulai bulan Maret - November 2008.

Tanah yang digunakan pada penelitian ini adalah tanah Regosol yang diambil di Pasir Jambak Lubuk Buaya Kecamatan Koto Tangah, Kota Padang. Bahan yang digunakan adalah benih selada varietas Panorama. Sebagai perlakuannya adalah pupuk organik kompos sampah kota dan pupuk anorganik Urea, TSP dan $\mathrm{KCl}$. Untuk pencegahan hama dan penyakit digunakan Curater $3 \mathrm{G}$, Curacron 500 EC dan Dithane M-45 dan sejumlah bahan kimia yang akan digunakan untuk analisis tanah dan tanaman di Laboratorium.

Penelitian ini dilakukan dalam bentuk percobaan pot di Rumah Kaca dengan menggunakan rancangan Faktorial 4 x 4 dengan 3 ulangan dalam Rancangan Acak Lengkap ( RAL ), yang terdiri dari 2 faktor. Setelah diuji dengan uji F ( Fisher Test ) pada taraf $5 \%$ dilanjutkan dengan uji BNJ ( Beda Nyata Jujur ). Perlakuan yang diberikan adalah:

Faktor I adalah takaran kompos sampah kota yang terdiri dari:

$$
\begin{aligned}
& \mathrm{K}_{0}=\text { Tanpa kompos sampah kota } \\
& \mathrm{K}_{1}=2,5 \text { ton/ha }(10 \mathrm{~g} / \mathrm{pot}) \\
& \mathrm{K}_{2}=5 \text { ton/ha }(20 \mathrm{~g} / \mathrm{pot}) \\
& \mathrm{K}_{3}=10 \text { ton/ha }(40 \mathrm{~g} / \mathrm{pot})
\end{aligned}
$$

Faktor II adalah takaran pupuk NPK yang terdiri dari:

$$
\begin{aligned}
& \mathrm{P}_{0}=\text { Tanpa pupuk anorganik } \\
& P_{1}=25 \% \text { Rekomendasi ( Urea, TSP, } \\
& \mathrm{KCl} \text { ) } \\
& \mathrm{KCl} \text { ) } \\
& \mathrm{P}_{2}=50 \% \text { Rekomendasi ( Urea, TSP, } \\
& \text { TSP, } \mathrm{KCl} \text { ) }
\end{aligned}
$$

Pelaksanaan Penelitian meliputi : 1). Persiapan Kompos, 2). Persiapan Media Tanam, 3). Persiapan Bibit dan Penanaman, 4). Pemberian Pupuk, 5). Pemasangan Label dan Tiang Standar, 6). Pemeliharaan dan 7). Panen.

Pengamatan, meliputi : analisis tanah dan pengamatan tanaman (tinggi tanaman, bobot kering tanaman, serapan N, $\mathrm{P}$ dan $\mathrm{K}$ tanaman.

\section{HASIL DAN PEMBAHASAN}

\section{Analisis Tanah Sebelum Inkubasi}

Hasil analisis tanah awal sifat kimia dan fisika Regosol Pasir Jambak Lubuk Buaya Kecamatan Koto Tangah, Kota Padang, sebelum diberi perlakuan pada penelitian ini disajikan pada Tabel 1 .

Berdasarkan hasil analisis tanah awal yang terlihat pada Tabel 1, dapat dinyatakan bahwa Regosol dilokasi Pasir Jambak Lubuk Buaya Kecamatan Koto Tangah, Kota Padang, merupakan tanah yang memiliki tingkat kesuburan yang rendah seperti yang terlihat dari hasil sifat kimia tanah; $\mathrm{pH}$ yang masam; $\mathrm{C}$-organik, $\mathrm{P}$ tersedia, KTK, K-dd dan Mg-dd yang rendah; N-total dan Ca-dd yang sangat rendah; Nisbah C/N dan Na-dd yang sedang. Sedangkan dari hasil analisis sifat fisika tanahnya, tanah bertekstur pasir berlempung menurut segitiga tekstur.

Bahan organik dapat meningkatkan kesuburan tanah dan sifat kimia tanah. Sesuai dengan pendapat Hakim et al. (1986) yang menyatakan bahwa bahan organik di dalam tanah berperan penting dalam memperbaiki kesuburan tanah, baik dari segi fisika, kimia maupun biologi tanah. Hardjowigeno (2003) juga menambahkan bahwa tanah-tanah yang sangat miskin, tanah pasir atau tanah yang banyak tererosi lebih baik dipupuk dengan pupuk organik dari pada pupuk buatan. Hakim et al. (1986) menyatakan bahwa bahan organik mempunyai daya jerap air yang besar, sehingga pemberian bahan organik pada tanah bertekstur pasir mampu meningkatkan daya kohesi antara partikel pasir sehingga menjadi tidak poros. 
Tabel 1. Hasil analisis tanah awal beberapa sifat kimia dan fisika Regosol

\begin{tabular}{clcc}
\hline No. & \multicolumn{1}{c}{ Jenis Analisis } & Nilai & Kriteria **) \\
\hline \hline & Kimia Tanah: & & \\
1. & $\mathrm{pH} \mathrm{H} \mathrm{H}_{2} \mathrm{O}(1: 1)$ & 4,81 & Masam \\
& $\mathrm{pH} \mathrm{KCl} \mathrm{(1:1)}$ & 4,50 & - \\
2. & C-organik (\%) & 1,10 & Rendah \\
3. & N-total (\%) & Sangat rendah \\
4. & Nisbah C/N & Sedang \\
5. & P-tersedia (ppm) & 15,71 & Rendah ***) \\
6. & KTK (me/100 g) & 8,55 & Rendah \\
7. & Kation-kation basa: & 9,89 & Rendah \\
& K-dd (me/100 g) & 0,19 & Sedang \\
& Na-dd (me/100 g) & 0,64 & Rendah \\
& Mg-dd (me/100 g) & 0,57 & Sangat rendah
\end{tabular}

Fisika Tanah:

8. Tekstur:

$\begin{array}{lrl}\text { Pasir }(\%) & 81,24 & \\ \text { Debu }(\%) & 9,38 & \text { Pasir berlempung *) } \\ \text { Liat }(\%) & 9,38 & \end{array}$

*) Sumber: Diagram Segitiga Tekstur Tanah (Hakim et al., 1986)

**) Sumber: Staf Pusat Penelitian Tanah Bogor (1983; cit. Hardjowigeno, 2003)

***) Sumber: Team 4 Architects \& Cunsulting Engineers bekerjasama dengan Fakultas Pertanian Universitas Andalas (1981)

\section{Analisis Tanah Setelah Inkubasi}

Hasil analisis sifat kimia Regosol Pasir Jambak Lubuk Buaya Kecamatan Koto Tangah, Kota Padang setelah diberi perlakuan dan diinkubasi selama 2 minggu dengan beberapa takaran kompos sampah kota disajikan pada Tabel 2.

Pada Tabel 2 dapat dilihat bahwa dengan peningkatan takaran kompos sampah kota memberikan pengaruh yang nyata terhadap Ca-dd dan Mg-dd. Peningkatan Cadd tanah akibat pemberian kompos sampah kota sebanyak 10 ton/ha (40 g/pot) adalah sebesar 0,46 me/100 g dan peningkatan $\mathrm{Mg}$ dd tanah akibat pemberian kompos sampah kota sebanyak 10 ton/ha (40 g/pot) adalah sebesar $0,12 \mathrm{me} / 100 \mathrm{~g}$ bila dibandingkan dengan tanpa pemberian kompos sampah kota. Jumlah kation dapat dipertukarkan yang diperoleh akibat pemberian bahan organik, erat hubungannya dengan sumbangan dari bahan organik dan kemampuan bahan organik dalam menghasilkan asam-asam organik. Menurut Hardjowigeno (2003) asam-asam organik 
Tabel 2. Hasil analisis tanah Regosol setelah diberi perlakuan dan diinkubasi selama 2 minggu

\begin{tabular}{ccccc}
\hline \multirow{2}{*}{ Sifat Kimia } & \multicolumn{4}{l}{ Perlakuan Kompos Sampah Kota (ton/ha) } \\
\cline { 2 - 5 } & 0 & 2,5 & 5 & 10 \\
\hline \hline pH H $2 \mathrm{O}(1: 1)$ & $4,86 \mathrm{a}$ & $4,89 \mathrm{a}$ & $4,93 \mathrm{a}$ & $5,03 \mathrm{a}$ \\
C-Organik (\%) & $1,79 \mathrm{a}$ & $1,40 \mathrm{a}$ & $1,52 \mathrm{a}$ & $1,53 \mathrm{a}$ \\
N-total (\%) & $0,08 \mathrm{a}$ & $0,09 \mathrm{a}$ & $0,10 \mathrm{a}$ & $0,13 \mathrm{a}$ \\
P-tersedia (ppm) & $10,30 \mathrm{a}$ & $11,55 \mathrm{a}$ & $12,79 \mathrm{a}$ & $15,71 \mathrm{a}$ \\
KTK (me/100 g) & $13,17 \mathrm{a}$ & $14,92 \mathrm{a}$ & $16,67 \mathrm{a}$ & $18,77 \mathrm{a}$ \\
Kation-kation basa: & & & & \\
K-dd (me/100 g) & $0,19 \mathrm{a}$ & $0,21 \mathrm{a}$ & $0,22 \mathrm{a}$ & $0,27 \mathrm{a}$ \\
Na-dd (me/100 g) & $0,65 \mathrm{a}$ & $0,67 \mathrm{a}$ & $0,68 \mathrm{a}$ & $0,82 \mathrm{a}$ \\
Mg-dd (me/100 g) & $0,57 \mathrm{~b}$ & $0,62 \mathrm{a}$ & $0,66 \mathrm{a}$ & $0,69 \mathrm{a}$ \\
Ca-dd (me/100 g) & $1,74 \mathrm{~b}$ & $1,81 \mathrm{~b}$ & $1,89 \mathrm{~b}$ & $2,20 \mathrm{a}$ \\
\hline
\end{tabular}

Angka-angka yang diikuti oleh huruf kecil yang sama menurut baris adalah berbeda tidak nyata menurut BNJ pada taraf $5 \%$

yang dilepaskan sebagai akibat dekomposisi bahan organik mempercepat pelapukan mineral yang banyak mengandung basa-basa.

Pemberian takaran sampah kota belum memberikan pengaruh yang nyata terhadap nilai $\mathrm{pH}, \mathrm{C}$ organik, $\mathrm{N}$ total, $\mathrm{P}$ tersedia, KTK, K-dd dan Na-dd Regosol Pasir Jambak Lubuk Buaya Kecamatan Koto Tangah, Kota Padang. Tetapi kalau dilihat dari angka-angka terjadi peningkatan $\mathrm{pH}$ tanah sebesar 0,17 satuan, , $\mathrm{N}$ total sebesar $0,05 \%, \mathrm{P}$ tersedia sebesar 5,41 ppm, KTK sebesar 5,60, K-dd sebesar 0,09 me/100 g, Na-dd sebesar 0,16 me/100 g serta penurunsn $\mathrm{C}$ organik sebesar $0,26 \%$ bila dibandingkan dengan tanpa pemberian kompos sampah kota.
Hasil Pengamatan Terhadap Tanaman Selada

Pertumbuhan tanaman

Dalam penelitian ini, pertumbuhan tinggi tanaman diamati secara visual dan direkam dengan foto (Gambar 1).

Pertumbuhan tanaman dalam penelitian ini juga diamati melalui tinggi tanaman. Dari pengamatan tidak ada pengaruh interaksi antara pemberian beberapa takaran kompos sampah kota dan takaran pupuk buatan terhadap tinggi tanaman selada. Hasil pengamatan tersebut disajikan pada Tabel 3.

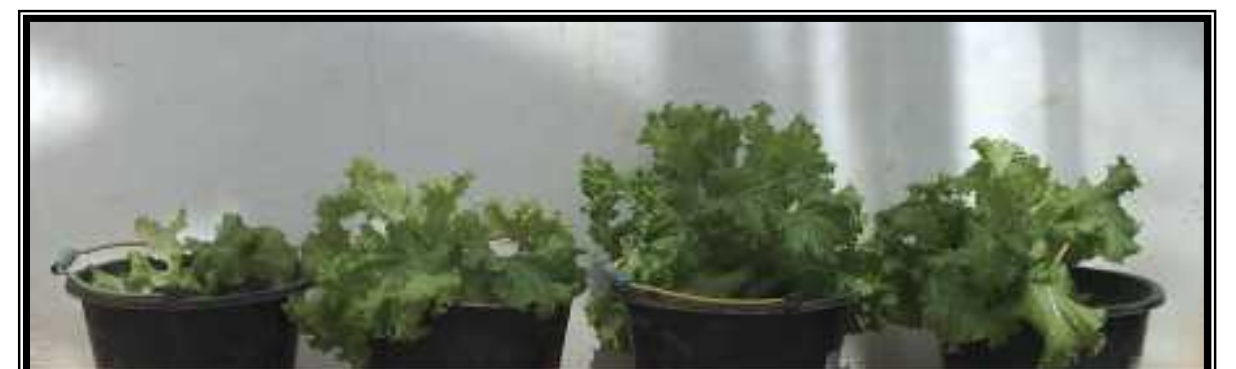



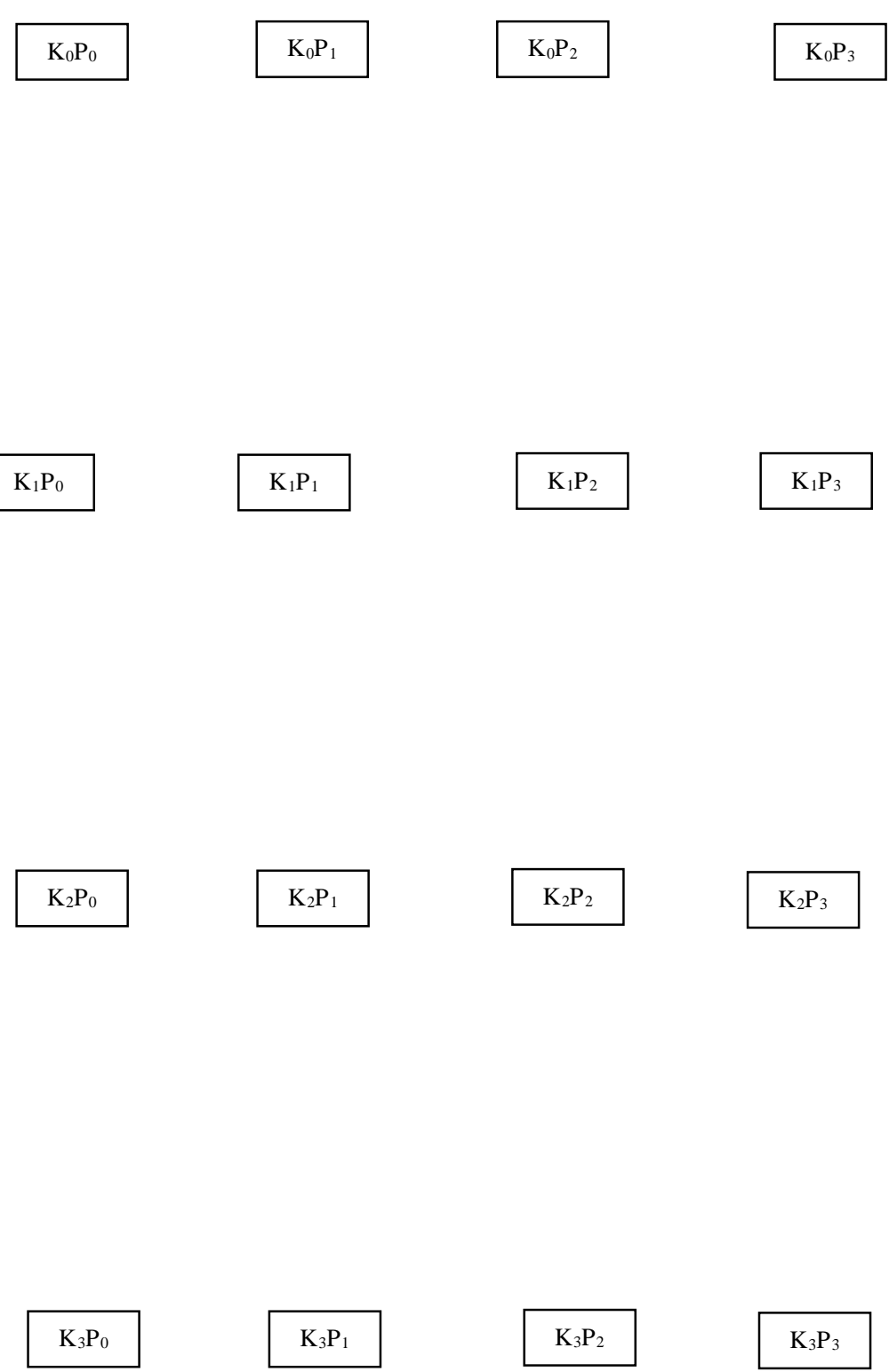

Gambar 1. Pertumbuhan tanaman selada yang dipengaruhi oleh takaran kompos sampah kota $\left(\mathrm{K}_{0}=\right.$ tanpa BO, $\mathrm{K}_{1}=2,5$ ton/ha, $\mathrm{K}_{2}=5$ ton/ha, $\mathrm{K}_{3}=10$ ton/ha $)$ dan pupuk NPK $\left(\mathrm{P}_{0}\right.$ $=$ tanpa pupuk, $\mathrm{P}_{1}=25 \% \mathrm{R}, \mathrm{P}_{2}=50 \% \mathrm{R}, \mathrm{P}_{3}=100 \% \mathrm{R}$ ) pada Regosol saat berumur 45 hari setelah tanam.

Tabel 3. Pengaruh pemberian takaran kompos sampah kota dan takaran pupuk buatan terhadap tinggi tanaman $(\mathrm{cm})$ pada Regosol Pasir Jambak Lubuk Buaya Kecamatan Koto Tangah, Kota Padang 


\begin{tabular}{lccccc}
\hline \multirow{2}{*}{$\begin{array}{l}\text { Kompos } \\
\text { (ton/ha) }\end{array}$} & \multicolumn{4}{l}{ Takaran Pupuk Buatan } & \\
\cline { 2 - 4 } & $0 \% \mathrm{R}$ & $25 \% \mathrm{R}$ & $75 \% \mathrm{R}$ & $100 \% \mathrm{R}$ & \\
\hline \hline & & & & \\
0 & 35.67 & 37.67 & 24.33 & 37.00 & $33.67 \mathrm{~A}$ \\
2,5 & 36.33 & 37.67 & 33.00 & 30.67 & $34.42 \mathrm{~A}$ \\
5 & 40.67 & 34.00 & 41.67 & 36.33 & $38.17 \mathrm{~A}$ \\
10 & 33.00 & 30.00 & 38.33 & 39.00 & $35.08 \mathrm{~A}$ \\
\hline Rata-rata & $36.42 \mathrm{a}$ & $34.83 \mathrm{a}$ & $34.33 \mathrm{a}$ & $35.75 \mathrm{a}$ & 35.33 \\
\hline
\end{tabular}

Angka-angka yang diikuti oleh huruf kecil yang sama menurut baris dan huruf besar yang sama menurut kolom adalah berbeda tidak nyata menurut BNJ pada taraf $5 \%$

Pada Tabel 3 terlihat bahwa tinggi tanaman yang terbaik pada takaran kompos sampah kota 5 ton/ha. Kalau dilihat dari takaran rekomendasi pupuk buatan adalah pada terlihat hasil 0 $\%$ rekomendasi yang lebih tinggi. Tapi ini kalau dilihat rata-rata hampir sama untuk semua rekomendasi, karena tidak berpengaruh nyata. Ini disebabkan karena ketersediaan unsur hara pada semua takatan, baik untuk sampah kota, maupun rekomendasi pupuk buatan.masih belum mencukupi kebutuhan untuk pertumbuhan tinggi tanaman unsur hara esensial seperti N, P dan K. Salisbury dan Ross (1995) menyatakan bahwa jika untuk mencapai kondisi pertumbuhan yang optimal dalam mencukupi kebutuhan tanaman, dilakukan peningkatan takaran pupuk yang berarti untuk pertumbuhan dan hasil tanaman.

3.b. Berat kering tanaman (g/pot)

Tabel 4. Pengaruh pemberian takaran kompos sampah kota dan takaran pupuk buatan terhadap berat kering tanaman pada Regosol Pasir Jambak Lubuk Buaya Kecamatan Koto Tangah, Kota Padang

\begin{tabular}{|c|c|c|c|c|c|}
\hline \multirow{2}{*}{$\begin{array}{l}\text { Kompos } \\
\text { (ton/ha) }\end{array}$} & \multicolumn{4}{|c|}{ Takaran Pupuk Buatan } & \multirow{2}{*}{ Rata-rata } \\
\hline & $0 \% \mathrm{R}$ & $25 \% \mathrm{R}$ & $75 \% \mathrm{R}$ & $100 \% \mathrm{R}$ & \\
\hline & \multicolumn{5}{|c|}{--------- berat kering (g/pot) ---------- } \\
\hline 0 & 8.61 & 17.22 & 12.30 & 8.20 & $11.58 \mathrm{~A}$ \\
\hline 2,5 & 11.07 & 11.89 & 9.43 & 11.48 & $10.97 \mathrm{~A}$ \\
\hline 5 & 10.46 & 14.35 & 13.74 & 11.89 & $12.61 \mathrm{~A}$ \\
\hline 10 & 14.76 & 12.30 & 9.84 & 13.53 & $12.61 \mathrm{~A}$ \\
\hline Rata-rata & $11.22 \mathrm{a}$ & $13.94 \mathrm{a}$ & $11.33 \mathrm{a}$ & $11.28 \mathrm{a}$ & 11.94 \\
\hline
\end{tabular}

Angka-angka yang diikuti oleh huruf kecil yang sama menurut baris dan huruf besar yang sama menurut kolom adalah berbeda tidak nyata menurut BNJ pada taraf $5 \%$

Dari Tabel 4 dapat diketahui pemberian kompos sampah kota sebanyak
5 ton/ha (20g/pot) dan 10 ton/ha (40 g/pot) memberikan rata-rata hasil yang sama, yaitu 
$12,61 \mathrm{~g} /$ pot. Sementara kalau dilihat dari rekomendasi pupuk buatan yang diberikan rekomendasi $25 \%$ memberikan hasil yang tinggi yaitu 13,94 g/pot. Peningkatan berat kering tanaman ini menurut Thompson dan Troeh (1978 cit. Yanto, 1995) bahwa pemberian pupuk Urea, SP-36 dan $\mathrm{KCl}$ dapat meningkatkan ketersediaan hara dalam tanah sehingga laju pengambilan unsur hara oleh tanaman meningkat dan meningkatkan berat kering tanaman

Tabel 5. Pengaruh pemberian takaran kompos sampah kota dan takaran pupuk buatan terhadap angkutan N, P dan K pada Regosol Pasir Jambak Lubuk Buaya Kecamatan Koto Tangah, Kota Padang

\begin{tabular}{|c|c|c|c|c|c|}
\hline \multirow{2}{*}{$\begin{array}{l}\text { Kompos } \\
\text { (ton/ha) }\end{array}$} & \multicolumn{4}{|c|}{ Takaran Pupuk Buatan } & \multirow{2}{*}{ Rata-rata } \\
\hline & $0 \% \mathrm{R}$ & $25 \% \mathrm{R}$ & $75 \% \mathrm{R}$ & $100 \% \mathrm{R}$ & \\
\hline & \multicolumn{5}{|c|}{----- N tanaman (g/pot) ------- } \\
\hline 0 & 1.79 & 3.58 & 2.55 & 1.70 & $2.41 \mathrm{~A}$ \\
\hline 2,5 & 2.30 & 2.47 & 1.96 & 2.38 & $2.28 \mathrm{~A}$ \\
\hline 5 & 1.37 & 1.93 & 2.07 & 3.34 & $2.18 \mathrm{~A}$ \\
\hline 10 & 3.07 & 2.55 & 2.04 & 2.81 & $2.62 \mathrm{~A}$ \\
\hline \multirow[t]{2}{*}{ Rata-rata } & $2.13 \mathrm{a}$ & $2.63 \mathrm{a}$ & $2.16 \mathrm{a}$ & $2.56 \mathrm{a}$ & 2.37 \\
\hline & \multicolumn{5}{|c|}{-------- P tanaman (g/pot) -------- } \\
\hline 0 & 0.37 & 0.75 & 0.53 & 0.35 & $0.50 \mathrm{~A}$ \\
\hline 2,5 & 0.48 & 0.51 & 0.41 & 0.50 & $0.47 \mathrm{~A}$ \\
\hline 5 & 0.45 & 0.62 & 0.59 & 0.51 & $0.55 \mathrm{~A}$ \\
\hline 10 & 0.64 & 0.53 & 0.43 & 0.59 & $0.55 \mathrm{~A}$ \\
\hline \multirow[t]{2}{*}{ Rata-rata } & $0.49 \mathrm{a}$ & $0.60 \mathrm{a}$ & $0.49 \mathrm{a}$ & $0.49 \mathrm{a}$ & 0.52 \\
\hline & \multicolumn{5}{|c|}{-------- K tanaman (g/pot) --------- } \\
\hline 0 & 2.91 & 5.83 & 4.16 & 2.78 & $3.92 \mathrm{~A}$ \\
\hline 2,5 & 3.75 & 4.02 & 3.19 & 3.89 & $3.71 \mathrm{~A}$ \\
\hline 5 & 3.54 & 4.86 & 4.65 & 4.02 & $4.27 \mathrm{~A}$ \\
\hline 10 & 0.36 & 0.79 & 0.94 & 0.49 & $0.65 \mathrm{~A}$ \\
\hline Rata-rata & $5.00 \mathrm{a}$ & $4.16 \mathrm{a}$ & $3.33 \mathrm{a}$ & $4.58 \mathrm{a}$ & 3.14 \\
\hline
\end{tabular}

Angka-angka yang diikuti oleh huruf kecil yang sama menurut baris dan huruf besar yang sama menurut kolom adalah berbeda tidak nyata menurut BNJ pada taraf $5 \%$ 
3.c. Angkutan hara $\mathrm{N}, \mathrm{P}$ dan $\mathrm{K}$ tanaman selada

Pengaruh pemberian beberapa takaran kompos sampah kota dan takaran pupuk buatan terhadap angkutan hara N, P dan K tanaman selada dapat dilihat pada Tabel 5. Pada Tabel 5 terlihat bahwa angkutan hara $\mathrm{N}$ yang terbaik pada takaran kompos sampah kota 10 ton/ha. Kalau dilihat dari takaran rekomendasi pupuk buatan adalah pada terlihat hasil $25 \%$ rekomendasi yang lebih tinggi. Sedangkan angkutan hara P takaran kompos sampah kota 5 dan 10 ton/ha memperlihatkan hasil yang sama yaitu 0,55 g/pot. Kalau dilihat dari takaran rekomendasi pupuk buatan adalah pada terlihat hasil $25 \%$ rekomendasi yang lebih tinggi. Dan angkutan hara $\mathrm{K}$ yang terbaik pada takaran kompos sampah kota 5 ton/ha. Kalau dilihat dari takaran rekomendasi pupuk buatan adalah pada terlihat hasil $0 \%$ rekomendasi yang lebih tinggi.

Akar tanaman selada merupakan sistem akar serabut yang menyebar dangkal dekat permukaan tanah sehingga penyerapan unsur hara tidak optimal. Lakitan (2000) menyatakan bahwa sebagian besar unsur hara yang dibutuhkan tanaman diserap dari larutan tanah melalui akar; sistem perakaran tanaman dipengaruhi oleh sifat genetis tanaman yang bersangkutan. Peningkatan angkutan hara $\mathrm{P}$ meningkat seiring meningkatnya takaran kompos sampah kota karena pemberian kompos sampah kota juga dapat mengurangi fiksasi $\mathrm{P}$ sehingga kandungan P-tersedia tanah dapat meningkat dengan meningkatnya kandungan P-tersedia tanah. Hal ini sesuai dengan pendapat Husin (1986) bahwa bahan organik mampu menaikkan kandungan P-tersedia dan $\mathrm{N}$ total tanah. Hardjowigeno (2003) bahwa peningkatan angkutan $\mathrm{P}$ dan $\mathrm{N}$ juga disebabkan karena ada penambahan pupuk $\mathrm{KCl}$.

Secara kuantitatif dapat dilihat penambahan peningkatan angkutan hara $\mathrm{K}$ seiring dengan peningkatan kompos sampah kota. Menurut Nyakpa et al. (1988) menyatakan bahwa penambahan $\mathrm{K}$ dari bahan organik baik dari sisa-sisa tanaman atau hewan sangat penting dalam menjaga keseimbangan kadar K-dd dalam tanah. Hal ini dapat mempengaruhi $\mathrm{K}$ yang diserap oleh tanaman. Pemberian pupuk buatan telah terjadi peningkatan hara $\mathrm{K}$ bila dibandingkan dengan tanpa pemberian pupuk, walaupun belum memberikan pengaruh yang nyata. Hal ini disebabkan karena penambahan pupuk $\mathrm{KCl}$ akan meningkatkan serapan hara bagi tanaman serta juga meningkatkan angkutan hara $\mathrm{K}$, sehingga $\mathrm{K}$ lebih tersedia di dalam tanah. Buckman dan Brady (1982) mengemukakan $\mathrm{K}$ penting dalam menambah ketahanan tanaman terhadap penyakit dan memperkuat batang sehingga tidak mudah rebah serta merangsang pertumbuhan akar yang dapat meningkatkan daya serapan hara bagi tanaman.

\section{KESIMPULAN DA SARAN}

Dari hasil penelitian, pengaruh pemberian takaran kompos sampah kota dan takaran pupuk buatan N, P dan K terhadap sifat kimia Regosol dan produksi tanaman selada dapat disimpulkan bahwa:

1. Takaran kompos sampah kota 10 ton/ha memberikan hasil yang lebih tinggi untuk peningkatan $\mathrm{pH}$ tanah, $\mathrm{N}$ total, $\mathrm{P}$ tersedia, KTK, Ca-dd, Mg-dd, K-dd dan $\mathrm{Na}$-dd serta penurunan $\mathrm{C}$ organik.

2. Secara umum hasil yang baik untuk pertumbuhan tanaman, berat kering, angkutan $\mathrm{N}, \mathrm{P}$ dan $\mathrm{K}$ tanaman selada adalah kompos sampah kota 5 ton/ha dan $25 \%$ rekomendasi pupuk buatan.

Dari penelitian yang telah dilakukan, maka disarankan takaran kompos sampah kota yang diberikan pada tanah Regosol untuk tanaman selada adalah 5 ton/ha (20 g/pot) dengan penghematan pupuk buatan sebanyak $75 \%$ dari rekomendasi yang ada.

\section{DAFTAR PUTAKA}

Buckman, H.O. dan N.C. Brady. 1982. IImu Tanah. Soegiman, penerjemah. Jakarta. Bhratara Karya Aksara. Terjemahan dari: The Nature and Properties of Soils. 788 halaman. 
Hakim, N., M.Y. Nyakpa, A.M. Lubis, M.A. Pulung, M.R. Saul, M.A. Diha dan G.B. Hong. 1984. Badan Praktikum Dasar-Dasar Ilmu Tanah. Badan Kerja Sama Ilmu Tanah BKS-PTN / USAID (University of Kentucky WUAE Projeck). 151 halaman.

Hardjowigeno, S. 2003. IImu Tanah (Edisi Baru). Jakarta. Akademika Pressindo. 286 halaman.

Husin, E.F. 1986. Pengaruh pupuk kandang dan $\mathrm{P}$ terhadap ketersediaan dan pembentukkan Nodula dan hasil kedelai (Glycine max L. M err) pada tanah Podzolik [Tesis]. Bandung. Fakultas Pasca Sarjana Universitas Padjajaran. 96 halaman.
Salisbury, F.B dan C.W. Ross. 1995. Fisiologi Tumbuhan III. Diah R. Lukman dan Sumaryono, penerjemah. Bandung. Institut Teknologi Bandung. Terjemahan dari: Plant Physiology. 342 halaman.

Sutedjo, M.M. 1999. Pupuk dan Cara Pemupukan. Jakarta. Rineka Cipta. 177 halaman.

Yanto, P. 1995. Peranan jamur pelarut fosfat (Aspergillus niger) dan takaran pupuk $\mathrm{P}$ terhadap ketersediaan dan serapan $\mathrm{P}$ tanaman cabai (Capsicum annum L) pada Ultisol Sitiung [Skripsi]. Padang. Fakultas Pertanian Universitas Andalas. 65 halaman. 